\title{
EL CONCEPTO DE RESIDENCIA HABITUAL DEL CAUSANTE EN EL REGLAMENTO SUCESORIO EUROPEO
}

\author{
THE CONCEPT OF THE DECEASED'S HABITUAL RESIDENCE IN THE \\ EUROPEAN SUCCESSION REGULATION
}

\author{
Javier Carrascosa González \\ Universidad de Murcia. España/Spain \\ carras@um.es
}

Recibido/Received: 12/01/2015

Modificado/Modified: 09/04/2015

Aceptado/Accepted: 27/04/2015

\begin{abstract}
RESUMEN
Las sucesiones mortis causa suscitan grandes cuestiones para el Derecho internacional privado. El presente trabajo aborda las relativas al foro general que determina los tribunales internacionalmente competentes para conocer de los litigios que suscitan estas sucesiones. En este marco, el concepto flexible, líquido y cambiante de "residencia habitual" del causante plantea problemas interpretativos de extrema importancia para los teóricos y los prácticos del Derecho internacional privado. Sin embargo, el presente ensayo mantiene que la liquidez del concepto de "residencia habitual del causante" puede constituir una ventaja para otorgar la competencia internacional a los tribunales del Estado miembro mejor situados para conocer del conjunto del pleito sucesorio internacional. Por otra parte, este trabajo sostiene, igualmente, que una cuidada exégesis del texto del Reglamento y una adecuada hermenéutica permiten asegurar los contornos del concepto, de modo que averiguar en qué país tuvo el causante su última residencia habitual no es tan complejo como, a primera vista, pudiera parecer.
\end{abstract}

\section{PALABRAS CLAVE}

Residencia habitual, sucesiones internacionales, norma de conflicto costes conflictuales, competencia judicial internacional, Derecho internacional privado europeo.

\section{SUMARIO}

1. Introducción. 2. Foro de la residencia habitual del causante. 2.1. Aspectos generales. 2.2. Concepto de "última residencia habitual del causante". Datos metodológicos previos. 2.3. Concepto de "última residencia habitual del causante". El "centro de la vida del causante". 2.4. Elementos constitutivos del concepto de "última residencia habitual del causante". 2.5. Acreditación de los elementos constitutivos del concepto de "última residencia habitual del causante". El mecanismo de la "evaluación general". 3. Reflexión final. Bibliografía.

\footnotetext{
ABSTRACT

International successions have often raised controversies for Private International Law. This paper deals with the general ground of jurisdiction of the deceased's last habitual residence. In this field, the flexible, fluid and changing concept of the last "habitual residence" of the deceased needs an appropriate interpretation both for academics and for the practitioners of Private International Law. However, this essay holds that the liquidity of the concept "habitual residence" of the deceased may be an advantage to grant international jurisdiction on the courts which are best placed to rule on the merits
} 
of the case. Moreover, this paper sustains that a careful and holistic interpretation of the text of the Regulation and a proper analysis of the function of this ground of international jurisdiction leads to a surprising conclusion, i.e., the concept of the "habitual residence" is not as complex and difficult to specify as, at first glance, it might appear.

\section{KEYWORDS}

Habitual residence, international successions, costs associated to the conflict rule, international jurisdiction, European private international law.

\section{CONTENTS}

1. Introduction. 2. Habitual residence of the deceased as a ground of international jurisdiction. 2.1. General remarks 2.2. Concept of "last habitual residence of the deceased". Methodological aspects. 2.3. Concept of "last habitual residence of the deceased". The "center of the deceased's life". 2.4. Basic elements of the concept "last habitual residence of the deceased". 2.5. Ascertaining of the basic elements of the concept "last habitual residence of the deceased". The "overall assessment". 3. Conclusive remarks. References.

\section{INTRODUCCIÓN}

El Reglamento (UE) 650/2012 del Parlamento Europeo y del Consejo de 4 julio 2012 relativo a la competencia, la ley aplicable, el reconocimiento y la ejecución de las resoluciones, a la aceptación y la ejecución de los documentos públicos en materia de sucesiones mortis causa y a la creación de un certificado sucesorio europeo (DOUE L201 de 27 julio 2012) constituye la norma central del Derecho europeo en la regulación de esta materia. Es conocido como el "Reglamento europeo sobre sucesiones" (RES). El carácter erga omnes del Reglamento 650/2012 y la primacía del Derecho de la UE sobre el Derecho interno de los Estados miembros son datos que constatan la importancia de este Reglamento. Nada será igual para los profesionales del Derecho internacional privado sucesorio tras el 17 agosto 2015, fecha en la que comenzará a aplicarse este Reglamento de manera íntegra. También los académicos deben abandonar viejas ideas trasnochadas para acoger los nuevos y casi futuristas planteamientos que, en ciertos aspectos, mantiene este Reglamento sucesorio europeo. Pues bien, el foro de la residencia habitual del causante constituye un punto cardinal en la intelección del Reglamento. Por ello, una reflexión medida, ponderada y sosegada sobre el concepto de "residencia habitual del causante" resulta oportuna en el ámbito de la competencia judicial internacional de las sucesiones mortis causa.

\section{FORO DE LA RESIDENCIA HABITUAL DEL CAUSANTE}

\subsection{Aspectos generales}

1. Los tribunales del Estado miembro en el que el causante tuviera su residencia habitual en el momento del fallecimiento tendrán competencia para resolver sobre la totalidad de la sucesión. Así lo indica el art. 4 RES. La residencia habitual del causante radica en el Estado miembro donde estaba situado el centro de interés familiar y social del causante (Cons. [24] RES). Este foro es subsidiario. Sólo opera si los tribunales del Estado miembro de la nacionalidad del causante carecen de competencia judicial internacional 
para conocer del litigio sucesorio (art. 7.a RES a contrario sensu). Diversas consideraciones son precisas en relación con el foro de la última residencia habitual del causante (art. 4 RES).

2. Como se ha indicado, este foro sólo se activa en el caso de que el foro de la nacionalidad del causante (art. 7 RES) no resulte operativo. Ello explica que el art. 4 RES lleve como rúbrica "competencia general" y no "foro prevalente" o "competencia principal". El Cons. [23] RES también se refiere a este foro de competencia judicial internacional como un "nexo general": "...el presente Reglamento debe establecer como nexo general, a efectos de la determinación tanto de la competencia como de la ley aplicable, la residencia habitual del causante en el momento del fallecimiento". Por ello, tal y como muy bien ha remarcado Feraci, se ha evaporado la inicial intención del legislador europeo de crear, en el Reglamento 650/2012, un "foro único general" que conduzca a individualizar un solo tribunal competente para los litigios sucesorios en los Estados miembros-. Ello habría evitado de manera total cualquier ejercicio de forum shopping. Al final, el resultado ha sido otro: un sistema de foros de competencia judicial internacional más bien híbrido o complejo en el que la residencia habitual del causante ha perdido fuerza como foro sucesorio. Ha pasado, en efecto, de querer ser un foro único, a constituir un foro subsidiario que debe convivir con otros foros (Feraci, 2013: 291-314).

3. Este foro sólo otorga competencia judicial internacional a los tribunales de un "Estado miembro". Si el causante tiene su residencia habitual en el momento del fallecimiento en un Estado no miembro de la UE, el foro recogido en este art. 4 RES no es operativo y no otorga competencia judicial internacional a ningún tribunal de ningún país.

4. Este foro evita el conflicto móvil, pues el art. 4 RES exige que el causante tuviera su residencia habitual en un Estado miembro "en el momento del fallecimiento". Residencias habituales anteriores no son relevantes a efectos del art. 4 RES. La nacionalidad del causante no es tampoco relevante a estos efectos. La Ley elegida, en su caso, por dicho causante para regular su sucesión $e x$ art. 22 RES, tampoco influye de ningún modo sobre este foro de competencia judicial internacional.

5. La competencia judicial internacional de los tribunales del Estado miembro de la última residencia habitual del causante es una competencia judicial internacional completa. En efecto, tales tribunales tendrán competencia para resolver "sobre la totalidad de la sucesión" (art. 4 RES). Queda por aclarar si esta competencia cubre también las cuestiones incidentales o previas. Puede afirmarse que, en tanto en cuanto sea preciso fallar sobre tales cuestiones para resolver la cuestión principal sucesoria, el tribunal dispone de tal competencia internacional. Lo fallado de modo incidental no debe producir efecto de cosa juzgada sobre dicha cuestión (Gaudemet-Tallon, 2013: 127-140).

6. Este foro otorga competencia judicial internacional a los tribunales de un Estado miembro. La precisión de la competencia territorial, funcional y objetiva constituye una cuestión a resolver con arreglo al Derecho Procesal del Estado miembro correspondiente a la última residencia habitual del causante.

7. Los tribunales del Estado miembro de la última residencia habitual del causante se encuentran en una situación óptima para conocer del pleito sucesorio. Por varias razones que pueden ser concretadas en las que siguen:

$1^{\circ}$ ) Los bienes que integran la herencia de una persona se encuentran, normalmente, en su totalidad o en su mayor parte, en el Estado donde el causante tenía su última residencia habitual (su último centro de vida social y familiar). Por tanto, los tribunales de dicho Estado miembro podrán desplegar su actividad jurisdiccional directamente sobre tales 
bienes sin necesidad de practicar pruebas o notificaciones judiciales en otros Estados. La ejecución de sus decisiones será directa ( $\sin$ necesidad de exequatur o similar, pues son decisiones "nacionales" en dicho Estado miembro).

$2^{\circ}$ ) Será frecuente que el causante haya dictado, en su caso, su testamento en el país de su última residencia habitual. Por ello, la localización, identificación y ejecución del testamento también se ve muy facilitada si los tribunales competentes para ello son los del Estado miembro de la última residencia habitual del causante (pues localizan, identifican, protocolizan y ejecutan un "testamento nacional").

$\left.3^{\circ}\right)$ No será extraño, por otro lado, que los presuntos beneficiarios de la herencia y los acreedores del causante o la mayor parte de ellos, tengan también su residencia habitual en el Estado de la última residencia habitual del éste. Por ello, en caso de litigio sucesorio, tales sujetos podrán "litigar en su propio país". Esa solución ahorra costes de litigación internacional a futuros posibles herederos y a los acreedores de la herencia.

$4^{\circ}$ ) La residencia habitual es un criterio con "visibilidad externa". Ello significa que los terceros, y en particular, los posibles herederos y legatarios, así como los acreedores de la herencia, pueden identificar y averiguar, de un modo sencillo, cuál es el Estado donde el causante tiene su residencia habitual. El Estado donde el causante tiene su centro de vida social y familiar (su residencia habitual) es un elemento fácilmente "visible para todos". Todos los interesados en la herencia pueden saber por anticipado y con cierta simplicidad, cuál es el Estado miembro de la residencia habitual del causante, y por tanto, cuáles son los tribunales que van a conocer, en su caso, de un posible litigio sucesorio. El criterio del residencia habitual presenta una visibilidad externa para terceros más elevada la que puede mostrar el criterio de la nacionalidad del causante o el criterio del domicile inglés. El causante, en efecto, puede haber cambiado de nacionalidad de "un modo oculto". Pude suceder, incluso, que le sujeto haya cambiado de nacionalidad sin que dicho cambio se haya hecho constar en un concreto Registro Civil. En tal caso, los terceros no saben ni pueden saber de un modo sencillo cuál es la nueva nacionalidad del causante. Por el contrario, la residencia habitual es un "criterio fáctico externo". Si el causante cambia de Estado de residencia habitual, dicho cambio es visible, evidente, y manifiesto para todos los particulares con intereses en relación con la herencia. El legislador europeo ha empleado el foro de la residencia habitual como "regla general" (art. 4 RES) y no el de la nacionalidad del causante, también, porque dicho criterio ayuda a la "precisión prospectiva" de los tribunales competentes para terceros en asuntos sucesorios.

$5^{\circ}$ ) El criterio de la residencia habitual del causante evita "discriminaciones legales" entre causantes y entre sucesiones. En efecto, todos los causantes integrados en una sociedad (sociedad del país de su residencia habitual) son tratados del mismo modo sea cual fuere su nacionalidad desde el punto de vista del acceso a los tribunales de Justicia. Se trata de un foro de competencia judicial internacional estrictamente neutral para todos los sujetos con intereses en una sucesión mortis causa. No favorece ni a unos ni a otros causantes. El criterio de la residencia habitual impide que, en los Estados miembros, se trate mejor a las sucesiones de los nacionales que a las sucesiones de los extranjeros.

\subsection{Concepto de "última residencia habitual del causante". Datos metodológicos previos}

1. La precisión del Estado donde el causante tiene su residencia habitual en el momento de su fallecimiento constituye una cuestión de extrema importancia para el correcto funcionamiento del entero sistema de competencia judicial internacional del Reglamento $650 / 2012$. Varios datos previos deben tenerse presentes al respecto. 
$\left.1^{\circ}\right)$ Falta de definición legal de la "residencia habitual". El Reglamento 650/2012 no define qué debe entenderse por "residencia habitual". El Cons. [23] RES indica, tan sólo, que la residencia habitual debe revelar "un vínculo estrecho y estable con el Estado de que se trate teniendo en cuenta los objetivos específicos del presente Reglamento". Debe recordarse que, en realidad, y como ha destacado Damascelli, los textos legales internacionales de DIPr. posteriores a la Segunda Guerra Mundial y en particular, los llamados "Convenios de La Haya" (elaborados por la Conferencia de La Haya de Derecho internacional privado) y también los textos normativos de Derecho de la UE, nunca han definido legalmente la noción "residencia habitual" (Damascelli, 2013: 87-103). Esta tradicional "falta de definición" se explica porque el criterio "residencia habitual" fue elegido ante la inconveniencia de fijar como punto de conexión el "domicilio". En efecto, el domicilio se define de manera distinta de país a país: cada Estado tiene su concepto de domicilio y las diferencias entre el "concepto continental" de "domicilio" y el "concepto anglosajón" del mismo son muy acentuadas (Lagarde, 2005: 1686-1708). Para no proporcionar "otro concepto más" de "domicilio", todos estos textos internacionales optaron por la noción "residencia habitual" y quedó claro que el nuevo concepto no sería definido, sino que debería ser concretado "caso por caso". También se desechó de raíz la idea de fijar como criterio de competencia internacional el "domicilio" del causante a definir por el Derecho nacional del Estado al que pertenece la autoridad que conoce del asunto. Es ésta la solución, realmente compleja y relativista, seguida, para las personas físicas, por el art. 59 RB-I.

$2^{\circ}$ ) Interpretación del silencio legal del Reglamento 650/2012 [sucesiones mortis causa] sobre el concepto de "residencia habitual". Este silencio legal en el Reglamento 650/2012 [sucesiones mortis causa] puede estar justificado por dos razones: (a) El legislador europeo, pudiendo haber definido el concepto no lo ha hecho porque ha preferido que sean los tribunales que apliquen el Reglamento 650/2012 los que suministren el concepto específico de residencia habitual del causante con atención a los casos concretos (= el concepto se construye por "grupos de casos" de similares características según se presenten ante las autoridades públicas y en particular, ante los tribunales de justicia). Una definición legal rígida y concreta se demostraría siempre, al final, como lagunosa y compleja, poco adaptada a los supuestos difíciles y susceptible de interpretaciones divergentes por tribunales de los distintos Estados miembros. La rigidez del concepto, paradójicamente, hubiera llevado a la incerteza legal, como bien indican Davì y Zanobetti (2013). Por ello se puede afirmar que el concepto de residencia habitual es un concepto adaptable a las circunstancias de hecho, un concepto de textura abierta; (b) El legislador europeo no ha indicado que el concepto de "residencia habitual" que emplea el Reglamento 650/2012 sea el mismo que utilizan otros Reglamentos europeos, como el Reglamento 2201/2003, el Reglamento Roma I o el Reglamento Roma II, por ejemplo. Ello puede explicarse por la razón de que el mismo concepto de "residencia habitual" debe concretarse de maneras distintas según el "tipo de litigio" del que se trate, apunta RichezPons (2005: 149-160). Es, pues, una noción con contenido variable ("notion à contenu variable") en feliz expresión de Carbonnier (1984: 99 y ss). De hecho, el mismo Cons. [23] RES indica, de modo expreso, que la residencia habitual debe concretarse "....teniendo en cuenta los objetivos específicos del presente Reglamento". En otras palabras, el concepto de la residencia habitual del causante debe precisarse en un "contexto sucesorio europeo", que es diferente de otros contextos legales (como el contexto de la "protección de menores", del "divorcio", o de los "contratos internacionales", por ejemplo). 
$\left.3^{\circ}\right)$ Concepto europeo de "residencia habitual". El concepto de "última residencia habitual del causante" es un concepto autónomo y propio del Reglamento 650//2012, ya que sólo un concepto uniforme europeo garantiza la aplicación uniforme de dicho Reglamento. Esto es, debe ser un concepto que no debe extraerse de ningún concreto Derecho nacional.

$\left.4^{\circ}\right)$ Concepto europeo variable por materias. Según expone Lagarde, el concepto de residencia habitual es siempre el mismo en todos los instrumentos legales de la UE (Lagarde, 2012: 691-732). Se trata del lugar donde radica el "centro de vida de la persona" ("le centre de vie de l'intéressé"). Ahora bien, el modo de concretar cuál es el concreto Estado en el que una persona tiene su residencia habitual varía según la materia e instrumento legal considerado. De ese modo, la residencia habitual se perfila de una manera distinta en el ámbito de la protección de niños (Reglamento 2201/2003) y de otra manera bien diferente en el área de los contratos internacionales (Reglamento Roma I), de los ilícitos extracontractuales (Reglamento Roma II), del divorcio (Reglamento 1259/2010 Roma III) y en el ámbito sucesorio (Reglamento 650/2012). El contexto social y jurídico reviste una extrema importancia. Por tanto, en lo que afecta a este último instrumento legal, la residencia habitual debe especificarse de un modo particular, pues interesa la residencia habitual a efectos sucesorios, no a efectos contractuales o de divorcio. En tal sentido, por ejemplo, cuando se trata de concretar la residencia habitual de un cónyuge en un litigio de divorcio, los elementos a valorar son distintos de los que deben evaluarse para concretar el país donde se encuentra el centro de vida (residencia habitual) del causante, como muestra Lagarde (2012: 691-732). Por tanto, para precisar el concepto de residencia habitual "del causante", debe tenerse en cuenta: (a) El contexto en el que se inserta el concepto (interpretación sistemática: el "contexto sucesorio europeo"); (b) El objetivo que persigue la normativa europea que emplea dicho concepto (interpretación teleológica: la seguridad jurídica en la precisión del tribunal competente y de la Ley aplicable a la sucesión, la libre circulación de decisiones en el ámbito sucesorio, la buena administración de la Justicia o "correcta administración de justicia" en la UE a la que refiere el Cons. [23] RES, el buen funcionamiento del mercado interior, la supresión de obstáculos a la libre circulación las personas que en relación con el ejercicio de sus derechos en situaciones de sucesión mortis causa con repercusiones transfronterizas, la buena organización prospectiva de la sucesión por parte del causante, la garantía de los derechos de herederos, legatarios, personas próximas al causante, y de los acreedores de la herencia) (Cons. [7] RES).

\section{3. Concepto de "última residencia habitual del causante". El "centro de la vida del causante"}

La residencia habitual del causante es, como se ha indicado, el lugar donde radica el "centro de vida" de la dicha persona. El Estado miembro de la "última residencia habitual del causante" es el Estado miembro donde éste tenía "el centro de interés de su familia y su vida social" (Cons. [24] RES). Dicho esto, ciertos aspectos de este concepto merecen una atención específica.

$\left.1^{\circ}\right)$ La idea básica: la integración social de la persona. La "última residencia habitual" del causante (art. 4 RES) debe identificarse con el "Estado miembro en el que el causante tenía una integración en un entorno social y/o familiar". Cuando una persona dispone de un "centro de vida personal y familiar" localizado en un concreto Estado es porque está integrado en el entorno de dicho Estado desde un punto de vista familiar y social. Es claro que "centro" e "integración" son conceptos referidos a la misma idea (el "centro" se 
encuentra rodeado por el resto y la integración supone inmersión en una entidad más amplia). La idea básica de la noción residencia habitual radica en la "integración real" de la persona en un medio social y jurídico determinado. En suma, la "residencia habitual" indica el "arraigo real entre una persona y un concreto medio socio-jurídico" (Espinar Vicente, 1995: 4379-4985). La "residencia habitual" refleja la "vinculación más estrecha" de un sujeto con un país determinado, un vínculo real entre el sujeto y un medio social concreto (Richez-Pons, 2005: 149-160).

$\left.2^{\circ}\right)$ Los precedentes romanos. Este concepto de residencia habitual, compuesto por los dos anteriores elementos, procede del concepto de "domicilium" del Derecho Romano clásico. En efecto, como indica la famosa regla de Servio-Ulpiano, "domicilium est, ubi quis degitet rerum suarum summam constituit eo consilio, ut ibi meneat" ("el domicilio es el lugar donde uno vive y tiene a voluntad el conjunto de sus cosas, con el fin de permanecer allí"). En el Codex de Justiniano se encuentra una definición muy parecida: "Domicilium est ubi quis degit rerunmque suarum summam constituit eo consilio, ut ibi maneat" (Codex, Lib. X, Título XXXIX, Ley 7), de traducción similar.

$\left.3^{\circ}\right)$ La residencia habitual es un "concepto referente a los datos de realidad" (Espinar Vicente, 1995: 5876-5880). Ello se explica por una histórica disputa metodológica propia del Derecho internacional privado, perfecta y críticamente expuesta por Cavers (1971/1972: 475-493). El concepto de "residencia habitual" nació para superar la rivalidad entre los puntos de conexión "nacionalidad" (defendido por los países latino-germánicos) y "domicilio" (sostenido por los países escandinavos y anglosajones y entendido como "legal headquarters"). Tras la segunda guerra mundial, la conferencia de La Haya de DIPr. optó por el criterio "residencia habitual". De ese modo se evitaba el punto de conexión "nacionalidad", que no siempre conducía a una Ley y a unos tribunales realmente conectados con el caso en cuestión. Ya también se evitaba el punto de conexión anglosajón del "domicile". El domicile es un concepto plagado de oscuridades y sutilezas en el que operan enrevesadas ficciones legales, formalidades jurídicas y que, además, no garantiza una auténtica integración real del sujeto con el país donde, según la Ley, tiene su "domicile". Para acreditar la residencia habitual del causante es preciso, como se ha indicado, acudir solamente a "datos de la realidad". En este sentido, deben ponerse de relieve diversos supuestos que, aunque pudieran aparentar que constituyen una "residencia habitual", no necesariamente lo son.

(a) Sujetos sin documentación de extranjería en regla. Resulta irrelevante, a efectos del precisar la residencia habitual del causante en un Estado miembro, el hecho de que tal residencia habitual sea "legal" o "ilegal". Por tanto, el hecho de que el sujeto carezca de "autorización de residencia" y/o de "autorización de trabajo" en un concreto Estado miembro, no significa, automáticamente, que no tenga su residencia habitual en dicho país. Y a la inversa: si el sujeto dispone de "autorización de residencia" y/o de "autorización de trabajo" en un Estado miembro, ello no significa que, por tal hecho, deba entenderse que, automáticamente, tiene en dicho Estado su "residencia habitual".

(b) Irrelevancia del domicilio fiscal o administrativo y de la inscripción en el padrón municipal. A efectos del art. 4 y 21 RES, es irrelevante el "domicilio fiscal" o "administrativo" del sujeto en un determinado Estado. Dicho "domicilio físcal" o "administrativo" sólo surte efectos fiscales o administrativos y no efectos de Derecho Privado. En relación con España puede afirmarse que la "inscripción en el padrón municipal de habitantes" de un municipio español no supone, automáticamente, que dicho sujeto tenga su residencia habitual en España (STS CA 11 noviembre 2009, STS 14 
septiembre 2009, STS CA 8 marzo 1983, STS 10 junio 1966, STS 4 mayo 1977, STS 15 noviembre 1991, STS 30 enero 1993, SAP Madrid 5 julio 2002).

(c) Irrelevancia de la vecindad civil del demandado. Es indiferente, a efectos del art. 4 y 21 RES, la vecindad civil que pueda ostentar el sujeto español y la carencia de vecindad civil de un extranjero que tiene su residencia habitual en España (STS 11 noviembre 1991, SAP Barcelona 1 noviembre 2003).

$\left.4^{\circ}\right)$ Críticas al "carácter líquido" del criterio "residencia habitual del causante". Ciertos expertos, como es el caso de D.F. Cavers, han enfatizado que el criterio de la "residencia habitual del causante" es, desde el punto de vista legal, más inseguro que el criterio "nacionalidad del causante" a la hora de ser empleado como foro de competencia judicial internacional y como punto de conexión de la norma de conflicto (Cavers, 1971/1972: 482). En efecto, diversas dudas sobre la "calidad conflictual" del criterio "residencia habitual del causante" deben recordarse, tal y como sugiere Devaux (2013): (a) Resulta mucho más sencillo cambiar de residencia habitual que cambiar de nacionalidad. En este sentido, la precisión de la competencia internacional y de la Ley aplicable a la sucesión mortis causa se hace difícil y cambiante; (b) La acreditación de la nacionalidad, se dice, es más sencilla que la acreditación de la residencia habitual. Acreditar ésta exige el desarrollo de un proceso de evaluación general de las circunstancias del causante: no basta con exhibir un pasaporte en vigor de un concreto Estado; (c) Ciertos profesionales, como los notarios, tendrán que decidir en qué país se halla la residencia habitual del causante sobre la base de datos suministrados por herederos o presuntos herederos, lo que puede dar lugar a resultados sesgados. Naturalmente, la concreción de la residencia habitual del causante en estos casos estará sujeta a responsabilidad profesional. Por otro lado, y como ya se ha avanzado, el criterio "residencia habitual" empleado por el Reglamento 650/2012 [sucesiones mortis causa] no tiene nada que ver con la "residencia a efectos fiscales", concepto que, además, varía de Estado a Estado. Sin embargo, es posible e incluso probable que los herederos insistan en "situar" la residencia habitual del causante en aquel Estado cuyos criterios fiscales resulten más benignos; (d) El "carácter líquido" de la residencia habitual del causante incitará, en frecuentes ocasiones, a una litigación entre los herederos en torno a la precisión del país de la última residencia habitual del causante. No se litigará por cuestiones sucesorias, como la legítima, la partición, la nulidad del testamento, una donación colacionable, la validez de un legado, etc. Se litigará por la determinación de la residencia habitual del causante, ya que de ello dependerá la precisión de los tribunales competentes y de la Ley aplicable a la sucesión mortis causa. La litigación se complica, así, con sutiles cuestiones preliminares. La litigación en torno a los criterios de competencia internacional y en torno a los puntos de conexión de la norma de conflicto aporta un carácter artificial al proceso. Complica el proceso, lo encarece y lo ralentiza.

\subsection{Elementos constitutivos del concepto de "última residencia habitual del causante"}

Con arreglo a la inmejorable propuesta metodológica de Damascelli (2013: 87-103), puede afirmarse que el concepto de residencia habitual en el Reglamento 650/2012 está integrado por dos elementos distintos. Ambos, en correcta combinación, revelan un vínculo del causante de carácter profundo, genuino y estable con un concreto Estado, de modo que pueda afirmarse que tal vínculo es expresión de la integración del causante en el 
ambiente social de dicho Estado. La combinación de ambos elementos pone de manifiesto cuál es el país donde el causante tenía su "centro social de vida".

$1^{\circ}$ ) Elemento objetivo (domus colere). Consiste en la presencia física del causante en un concreto Estado (domus colere: "habitar en una casa"). Este elemento presenta dos aspectos diferenciados.

(a) Aspecto cuantitativo. Debe valorarse, en primer lugar, la duración en el tiempo de la estancia de una persona en el territorio de un Estado. La presencia física debe ser "duradera". A ello se refiere el Cons. [23] RES, que indica que la autoridad que sustancie la sucesión debe tomar en consideración "...en particular la duración [...] de la presencia del causante en el Estado de que se trate". A efectos de la proyección práctica de este aspecto cuantitativo, las situaciones sucesorias pueden presentarse en tres diferentes.

Grado 1: persona sin estancia física alguna en un país. Un causante que no haya estado nunca presente de modo físico en un concreto Estado, no puede haber tenido su residencia habitual en dicho Estado. La mera voluntad de retornar a un país, la ilusión por vivir en un país, el vínculo emocional con un concreto país o nación, el hecho de que la familia del causante renta su residencia habitual en un concreto país en el que nunca ha estado el causante, son todos ellos elementos carentes de incidencia para fijar la residencia habitual del causante. Un causante no puede tener su residencia habitual en un país en el que no ha estado nunca o en el que ha estado en un momento anterior a su fallecimiento pero en el que ya no se encuentra en dicho momento. En este sentido, el criterio "residencia habitual" se diferencia del criterio anglosajón del "domicile" en que un causante puede tener o haber tenido su domicile en un Estado en el que nunca ha residido y en el que nunca ha estado. Sin embargo, ello no es posible en relación con la residencia habitual. El causante no puede haber tenido su residencia habitual en un país en el que nunca ha estado y en el que no ha tenido jamás una estancia ni una presencia física.

Grado 2: persona con una estancia física breve en un país. Una estancia temporalmente breve en un país determinado, esto es, una estancia reducida en el tiempo, objetivamente corta, exigua, en un país concreto no es suficiente para acreditar la concurrencia del primer elemento objetivo que compone la residencia habitual, esto es, la "presencia física". En tal caso, el sujeto no dispone, en realidad, de una "presencia física" en un país, sino de un mera "estancia efímera". No resulta posible fijar de modo matemático y apriorístico el número de "días" o semanas" que se exigen para considerar que una persona se halla en situación de "estancia breve" en un país o de "presencia duradera" en el mismo. Ello debe quedar a la prudente discreción y al sentido común del tribunal y dependerá del caso concreto, según indica la clásica y brillante aportación de de Winter (1969: 347-504), en el mismo sentido Cavers (1971,1972: 475-493) y van Hoogstraten (1967: 337-435). En suma, una estancia meramente fugaz en el tiempo, puramente pasajera, efímera, escueta, momentánea, transitoria, limitada, precaria, en un país determinado, no constituye una "presencia" en dicho país que resulte suficiente para acreditar el aspecto cuantitativo del domus colere necesario para hablar con propiedad de una residencia habitual. Puede citarse diversos ejemplos de mera "estancia física transitoria" de una persona en un país: (i) El hecho de atravesar un país durante unas días u horas de camino a otro país; (ii) Las "escalas de mero paso" por un aeropuerto o por un puerto marítimo o fluvial o por carretera; (iii) Las visitas fugaces escasos días o períodos cortos a un país y que obedecen, generalmente a motivos muy determinados y concretos en el tiempo, como el turismo, la asistencia médica, los estudios, las visitas lúdicas o por causas personales a familiares y/o 
amigos, motivos profesionales, económicos, o legales, por citar algunos, tampoco son más que una "estancia breve" y no una "presencia duradera".

Grado 3: persona con una presencia duradera en un país. Es preciso que el causante tenga una presencia duradera en un concreto país. Se trata de un dato objetivo: la persona debe "estar presente" en un país, es decir, debe encontrarse en un país de modo duradero, durante un tiempo perdurable, constante, prolongado, largo, extenso, amplio, dilatado, holgado, abundante. No se trata, como en las dos anteriores situaciones, de una mera "estancia", sino de una verdadera "presencia". El sujeto no sólo "está" en un país, sino que "está presente" en dicho país. Es claro que "estar en un país" no es "habitar en un país". Para "habitar en un país" se requiere una "presencia duradera", que es lo que se trata de acreditar a través de este aspecto cuantitativo del elemento objetivo de la residencia habitual. No se mide ni se valora en este momento la intención del sujeto al instalarse en un país. Tampoco se trata, en este momento metodológico, de medir si la presencia física del sujeto en un país es "temporal" o es "estable" o "permanente". De hecho, nadie puede decir que su presencia en un país será para siempre o lo será por un año, dos o diez. Lo que se valora es, exclusivamente, la duración temporal de su presencia en un país. Por ello, puede decirse que cuando una persona manifiesta una presencia duradera, continuada, prolongada y estable en un país, se cumple el aspecto cuantitativo del elemento objetivo de la residencia habitual. Se trata de calibrar ahora si la presencia es duradera en el tiempo, nada más. De este modo, por ejemplo, un ingeniero español que se traslada a vivir a Kuwait durante dos años para poner en marcha un proyecto hotelero muestra una "presencia física duradera" en dicho país. Cumple con la exigencia de "presencia" que requiere el aspecto cuantitativo del elemento objetivo de la residencia habitual. Su estancia en Kuwait es más que una "estancia", es una "presencia duradera".

(b) Aspecto cualitativo de la presencia física de una persona en un Estado. No resulta suficiente con la mera presencia física del causante durante un cierto tiempo, incluso muy prolongado o constante, en un concreto Estado, para afirmar que el sujeto dispone, en efecto, de su presencia física (domus colere) en dicho Estado. Esa presencia física incluso si es duradera, debe revestir, además, una "calidad específica". Debe exigirse que se trate de una presencia "profunda" o "integrada" en dicho Estado (= una "presencia de calidad social y cultural"). A ello se refiere el Cons. [23] RES al indica que la autoridad que sustancie la sucesión debe tomar en consideración "... en particular la [...] regularidad de la presencia del causante en el Estado de que se trate, así como las condiciones [...] de dicha presencia". Se deben valorar, en este momento metodológico, la naturaleza y las características de tal presencia duradera del causante en un país determinado (= la "regularidad" y las "condiciones"). Se trata de aclarar qué tipo de presencia duradera en un concreto país manifiesta el causante. Dicha valoración permitirá descubrir si el sujeto dispone de una "presencia integrada" en el país donde se encuentra físicamente. La locución tradicional romana lo explica muy bien. No se trata de poseer una "presencia duradera" en un país, sino de "habitar" en dicho país (= domus colere / el verbo latino "colo, ui, cultum, ere" significa "habitar"). Es obvio que "habitar" en un país reviste un carácter más profundo que "estar presente" en dicho país. La persona que habita en un país es la persona que está integrada en el contexto social y cultural de dicho país. Es la persona que tiene su casa (domus) en dicho país. Varios ejemplos puede ayudar a comprender el matiz: (i) Un escritor norteamericano que se aísla en una casa alquilada o en una suite de hotel situada en el Algarve portugués para escribir un libro, aunque pase allí tres años, no tiene residencia habitual en dicho país. No "habita" en Portugal. Simplemente, se encuentra en Portugal; (ii) Un sujeto inglés que habita de modo permanente en España pero que se 
relaciona exclusivamente con ciudadanos ingleses, que compra solamente en negocios regentados por ingleses, que acude únicamente a eventos organizados por connacionales ingleses, que no habla ninguna lengua española, etc., es una persona con una presencia "no profunda" en España. No puede afirmarse que tenga una "presencia de calidad" en España y no tendrá, por tanto, su residencia habitual en España. No está integrado en el ambiente social y cultural español.

$2^{\circ}$ ) Elemento intencional o subjetivo. Debe valorarse, en segundo lugar, la intención de la persona de fijar, en un concreto país, y con carácter estable, el centro de intereses de su vida familiar y profesional. La persona debe mostrar una intención de permanecer en un concreto lugar en el que dispone de una presencia duradera (animus manendi / settled purpose). Esa intención de permanecer se refleja en el Cons [23] RES, que exige una "regularidad" de la presencia del causante en el Estado de que se trate. Una presencia "regular" es una presencia "estable", esto una presencia acompañada del animus manendi del sujeto (de su voluntad de fijar su residencia en un Estado con vocación de permanecer en dicho Estado) (Bonomi, 2010: 605-610). Es preciso identificar con claridad, señala Nourissat, una voluntad libre del sujeto de querer establecer en un Estado concreto su centro familiar y social (Nourissat et al, 2013: 17-36). La "residencia habitual" de una persona comporta intrínsecamente un elemento volitivo que está siempre presente. La persona, voluntariamente, sitúa su centro vital en un Estado porque ha tomado la decisión libre de tener un "centro" de sus actividades sociales y familiares y de tenerlo en un concreto Estado con el que su vínculo es estable, duradero, regular y constante. A ello se refiere el Cons. [23] RES, que indica que la autoridad que sustancie la sucesión debe tomar en consideración "... en particular [...] los motivos de dicha presencia [del causante en el Estado de que se trate]...". Deben diferenciarse varios casos desde el prisma del "elemento intencional" de la residencia habitual.

(a) Traslados forzados a un país. La persona debe haber dejado clara su voluntad libre de habitar en un concreto lugar con vocación de permanencia. Se trata de una decisión libre del causante. El elemento subjetivo debe percibirse en la persona del causante. Es el causante el que debe decidir cuál es el país en el que quiere instalar su centro social de vida de modo estable y permanente. En consecuencia, si el causante ha sido inducido, forzado o engañado para, contra su voluntad o sin contar con su voluntad, transferirse de modo permanente a un concreto país, debe estimarse que ese causante no tiene su residencia habitual en dicho país. Puede ser útil recurrir al famoso ejemplo del "abuelo alemán en Zaragoza": visto que las residencias para ancianos son más económicas en España que en Alemania, si los hijos de un anciano alemán de 90 años que vive en Berlín deciden internarle, contra la verdadera voluntad de esta persona, en una residencia para la tercera edad situada en Zaragoza, debe considerarse que dicha persona no tiene intención de instalar su centro de vida en España. No tendrá su residencia habitual en España a efectos del Reglamento 650/2012. De igual modo, los menores que son obligados a trasladarse e instalarse permanentemente en países concretos, así como los presos y reclusos que están internados forzosamente en establecimientos de un país determinado, no han manifestado su intención personal y voluntaria de residir en dicho país. Su presencia duradera en un país no revela su intención de instalarse en dicho país. Por esta razón, no tendrán necesariamente su residencia habitual en tal Estado.

(b) Traslados voluntarios a un país sin intención de permanencia. Las personas que voluntariamente se trasladan a un país por motivos muy precisos que no implican su libre decisión de centrar su vida en dicho país, no tendrán en el mismo su residencia habitual. 
Éste es el clásico supuesto de los estudiantes. Así, un ciudadano francés que estudia en España durante seis meses al año y vive en París la otra mitad del año, no tiene su residencia habitual en España. No tiene ninguna intención de permanecer de forma estable en España. Por tanto, un período de estudios, perfectamente delimitado en el tiempo, en un país concreto, no refleja la voluntad del estudiante de instalarse en tal país, de modo que no tendrá en el mismo su residencia habitual. En este mismo sentido, un estudiante alemán que transcurre nueve meses al año en España y que regresa en vacaciones a Alemania con su madre, no tiene su residencia habitual en España, por mucho tiempo que transcurra en España, y por muy integrado que esté en España, con cuyos nacionales se relaciona habitualmente y aunque tenga novia española. Dicho estudiante tiene su residencia habitual en Alemania pues su presencia en España no refleja intención alguna del mismo de permanecer en España (Sent Bundesgerischtshof 5 febrero 1975) citada por autores como Damascelli (1975: 272-275) y Franzina y Leandro (2013: 87-103). En este mismo supuesto se encuentran los sujetos que transcurren períodos de tiempo limitados, más o menos extensos, en un país por puros motivos médicos, laborales, lúdicos, profesionales, visitas a parientes, y otros similares, aunque su presencia en dicho país sea duradera y prolongada e incluso si el sujeto está profundamente integrado en el ambiente social y cultural de dicho país.

\subsection{Acreditación de los elementos constitutivos del concepto de "última residencia habitual del causante". El mecanismo de la "evaluación general"}

1. Es claro que una cosa son los elementos que deben detectarse para poder hablar de residencia habitual (la presencia física duradera e integrada del causante en un concreto país y la intención de dicho sujeto de habitar con carácter permanente en tal país), y otra bien distinta es la prueba o acreditación de tales elementos constitutivos de la residencia habitual en un caso concreto. En consecuencia, son tres los elementos a acreditar: (a) La presencia física duradera en un concreto país; (b) La integración del causante en la sociedad de dicho país; (c) La intención del sujeto de habitar con carácter permanente en dicho país. Debe subrayarse que de los tres elementos a acreditar, el primero (la presencia física duradera del causante en un país) constituye una cuestión puramente cuantitativa que exige, únicamente, un cómputo del lapso temporal que el causante ha transcurrido en un país. Por tanto, lo que exige una prueba o verificación es, en primer lugar, la integración del causante en la sociedad de dicho país y en segundo lugar, la intención del sujeto de habitar con carácter permanente en dicho país. El Reglamento 650/2012 contiene una referencia al mecanismo técnico jurídico que debe utilizarse para determinar cuál es el país de la residencia habitual del causante, esto es, el país donde un causante tiene, por un lado, una "presencia física duradera e integrada" y, al mismo tiempo, la intención de permanecer en ese país. En efecto, el Cons. [23] RES indica que dicho procedimiento debe consistir en una "evaluación general de las circunstancias de la vida del causante durante los años precedentes a su fallecimiento y en el momento del mismo". Resulta necesario introducir varias precisiones metodológicas en torno a este procedimiento de "evaluación general".

$\left.1^{\circ}\right)$ La "evaluación" de los contactos. Se trata de una auténtica "evaluación" y no de un mero "recuento cuantitativo" de contactos del causante con un concreto Estado. El tribunal debe "valorar" (esto es, contar, pero sobre todo, ponderar), los contactos de un causante con los distintos Estados ("argumenta non sunt numeranda, sed ponderanda"). Esos contactos deben ser "evaluados" (la autoridad debe "tomar en consideración" tales contactos, dice el Cons. [23] RES). En efecto, el tribunal debe considerar "todos los hechos pertinentes" (Cons. [23] RES). Todos los contactos cuentan (el Cons. [23] RES se refiere a 
"todos" los hechos pertinentes", aunque unos cuentan, pesan o valen más que otros (el Cons. [23] RES se refiere a los hechos "pertinentes", no a los que nada o poco tienen que ver con la integración social y familiar del causante en un Estado miembro: hechos o contactos no pertinentes a efectos sucesorios, datos no relevantes en el contexto sucesorio). Lo anterior significa que no todos los contactos pesan (valen, cuentan) igual. Existen contactos y datos relevantes y contactos y datos menos relevantes a efectos sucesorios (hechos pertinentes y hechos no pertinentes, en palabras del Cons. [23] RES). En este sentido es necesario insistir en que la precisión de la residencia habitual depende, en todo caso, de las circunstancias del caso concreto del que se trate.

$\left.2^{\circ}\right)$ El contexto sucesorio y la elipse conceptual de la residencia habitual de Van Hoostraten. Como ha recordado J.M. Espinar Vicente (Espinar Vicente, 1980: 3-27; 1995: 5876-5880), resulta muy acertada la "metáfora de la elipse" de van Hoogstraten: "la vida de una persona, al igual que una elipse, puede tener más de un centro" (van Hoogstraten, 1967: 337-435). Como indica Carbonnier (1984: 99-121) la residencia habitual constituye una noción con contenido variable ("notion à contenu variable"). En efecto, una persona puede habitar con su familia en el país $\mathrm{X}$ pero tener sus negocios, y/o su patrimonio principal en otro país Z. En tal caso, su residencia habitual se localiza, a efectos familiares $\mathrm{y}$ personales, en el Estado $\mathrm{X}$, mientras que su residencia habitual a efectos profesionales y/o patrimoniales se encuentra en el Estado Z. Esta disociación operativa" de la residencia habitual resulta adecuada y útil. Permite detectar la mayor vinculación objetiva de una persona con un país según la materia del litigio, lo que impide una internacionalización ficticia de las relaciones jurídicas y su deslocalización artificial. Si una persona habita con su familia en el Estado X, parece lógico que las controversias jurídicas relativas a sus relaciones jurídicas familiares y personales se decidan ante los tribunales del Estado X y con arreglo a la Ley del dicho Estado, y no ante los tribunales del Estado Z y según la Ley de Z.

En consecuencia, una persona puede tener su "residencia habitual" en varios países al mismo tiempo. Ello dependerá del tipo de litigio que se considere y de las circunstancias del supuesto (SAP Madrid 5 julio 2002). Así, es posible indicar que: (i) En los litigios relativos al Derecho de familia, son importantes y relevantes los vínculos y contactos con uno o varios países que derivan de la vida personal del sujeto, como su nacionalidad, el país donde habita su familia, el país donde reside el hijo de la persona en cuestión; (ii) En los litigios relativos al Derecho Patrimonial, son relevantes los vínculos relativos a la actividad profesional o laboral del sujeto con uno o varios países, como el lugar donde radican los negocios, el lugar donde se centraliza la producción de la empresa, el lugar donde se concluyen los contratos, el lugar desde donde se dirige una empresa o explotación económica, o el lugar donde radican los activos de una empresa; $3^{\circ}$ ) En los litigios sucesorios, que es lo que ahora interesa, las dificultades son mayores. En efecto, los litigios sucesorios son litigios patrimoniales relativos al destino de la herencia del causante, pero en tales litigios están igualmente presentes intereses y circunstancias personales y familiares. El causante puede decidir el destino de sus bienes y la Ley, con frecuencia, establece reglas de asignación de tales bienes en favor de familiares. Por tanto, en los litigios sucesorios, cuentan tanto los factores de tipo personal como los factores de tipo patrimonial. Son importantes, así, los contactos de todo tipo del sujeto con uno o varios países, ya que la sucesión se refiere a aspectos tanto personales y/o familiares como patrimoniales. Es el "dilema sucesorio": todos los contactos, personales, familiares y patrimoniales, cuentan. De ahí la dificultad intrínseca del proceso de comprobación de la 
residencia habitual del causante en un país determinado. Ahora bien, sin descartar ningún tipo de dato o elemento, el Reglamento 650/21012 otorga una cierta prevalencia a los contactos de tipo familiar y social sobre los contactos de tipo profesional y patrimonial. Así se desprende del Cons. [24] RES, que se refiere al centro de interés de la familia y de la vida social del causante. En consecuencia, la última residencia habitual del causante a efectos del Reglamento 650/2012 está determinada por el centro de la vida familiar y social del causante y no por el centro de vida profesional, económico o patrimonial de dicho sujeto. Por ello, el art. 4 RES fundamenta la competencia judicial internacional de los tribunales de los Estados miembros en el "centro de vida social y familiar del causante" (en la integración social y familiar del causante), mientras que el art. 11 RES basa la competencia judicial internacional en el "centro de vida patrimonial del causante" (foro del Estado miembro de situación de los bienes de la herencia). Así, puede también aceptarse que el lugar de situación de los bienes de la herencia no es revelador, por sí mismo, de la "residencia habitual del causante".

$\left.3^{\circ}\right)$ Evaluación "general". Indica el Cons. [23] RES que esta evaluación de los contactos del causante con un concreto Estado miembro debe ser una "evaluación general". En efecto, se trata de "poner en relación" todos los elementos, datos y contactos del causante con diversos Estados. Un dato o contacto puede resultar significativo o importante para precisar el país de la residencia habitual del causante, pero no puede ni debe ser utilizado como "único dato". Dicho contacto debe evaluarse en relación con los demás datos, informaciones y contactos del sujeto con los distintos Estados. Ejemplo: del dato aislado de la compra de un inmueble del sujeto en un país $\mathrm{X}$ no debe inferirse de forma axiomática la residencia habitual del sujeto en dicho país.

$\left.4^{\circ}\right)$ Evaluación "temporalmente limitada". Esta evaluación debe limitarse a los elementos de contacto o circunstancias de la vida del causante "durante los años precedentes a su fallecimiento y en el momento del mismo" (Cons. [23] RES). En efecto, no debe olvidarse que se trata de concretar la residencia habitual del causante "en el momento del fallecimiento" de éste (art. 4 RES). Por ello no tiene sentido ni procede explorar la residencia habitual a través de elementos, datos, informaciones y circunstancias que se refieren a momentos temporales alejados en el tiempo respecto del momento del fallecimiento del causante. Antiguas y superadas residencias habituales del causante no resultan relevantes en este proceso argumentativo.

$5^{\circ}$ ) Datos concretos reveladores de la presencia física integrada del causante en un país y de la intención del mismo de habitar en dicho país con carácter permanente. Lo que debe ser evaluado por la autoridad competente son las "circunstancias de la vida del causante". En efecto, interesa descubrir la residencia habitual del causante, no de su familia o de otros sujetos (Cons. [23] RES). Por otro lado, como antes se ha avanzado, lo que resulta relevante es el conjunto de datos o circunstancias de la "vida del causante" (los datos de las "relaciones sociales y familiares del causante", más que los datos económicopatrimoniales del mismo). En esta línea, puede resultar útil distinguir.

(a) Datos útiles para constatar la integración del causante en la sociedad de un concreto país. Son relevantes las circunstancias que ponen de manifiesto las relaciones del causante con la sociedad de un país determinado. Son datos que revelan la integración social y familiar permanente del causante con un Estado concreto. Entre tales datos pueden citarse la inserción del causante en actividades y círculos sociales propios de ese país, sus relaciones personales con habitantes de dicho país, especialmente si se trata de relaciones familiares, su participación en la vida política de dicho país o ciudad de residencia, el dominio por parte del causante de la lengua del país en cuestión y su grado de seguimiento 
de las costumbres y hábitos del mismo, el lugar donde se halla el círculo de amistades del causante, lugar donde desarrolla su actividad relacional general, lugar donde reside su familia o los miembros relevantes de la misma, lugar donde reside su pareja, y otros similares. Igualmente, el hecho de que el causante viva en un inmueble de su propiedad sito en un Estado, muestra un peso mayor en la acreditación de su integración social, que una presencia del sujeto en un Estado en el que vive en un apartamento de alquiler o en precario.

(b) Datos útiles para constatar la intención del causante de residir con carácter permanente en un concreto país. Para acreditar el elemento intencional o subjetivo de la residencia habitual, resultan útiles diversas circunstancias externas tales como la apertura de una cuenta corriente bancaria en un banco de un determinado país para cargar a la misma los gastos cotidianos de la vida, la obtención de financiación de larga duración por parte de bancos de un país concreto, su trabajo estable en un país, firma de contratos de larga duración a ejecutar en ese país, etc.

(c) Contactos con menor peso argumentativo. Los contactos que presentan un menor peso en la argumentación necesaria para concretar la noción de residencia habitual del causante son los que, en sí mismos considerados, no denotan claramente una integración social y familiar del sujeto con un Estado en particular ni su intención de residir con carácter permanente en un país. En este sentido, los "datos meramente formales" podrán ser tomados en consideración para determinar el lugar de residencia habitual del causante, pero sólo en la medida en la que reflejen una auténtica integración de dicho sujeto con ese Estado. Las inscripciones registrales o en el padrón municipal de habitantes no presentan, por sí solas, ningún valor material que revele una residencia habitual del causante con el Estado en cuestión. La inscripción en un registro público puede y debe ser tenida en cuenta, pero, en sí mismo considerada, no dice nada que revele claramente una integración social y familiar del sujeto en el Estado de situación de dicho registro público. No es un "dato de la realidad" sino un "dato jurídico", que no tiene por qué coincidir con la verdad de la situación personal del causante. En consecuencia, la solicitud y en su caso obtención de permiso de residencia o inscripción en el Registro de extranjeros de un país determinado, y la solicitud y, en su caso, obtención de la nacionalidad de un concreto Estado, constituyen datos formales adicionales que pueden ser valorados para reforzar "datos de la realidad" que sí demuestran la integración social del causante con un país y su intención de residir permanentemente en dicho Estado.

$\left.6^{\circ}\right)$ Resultado de la "evaluación general". El mecanismo de la "evaluación general no es un capricho del legislador europeo. Dicho mecanismo constituye un sistema de valoración apropiado para poder acreditar la existencia de un "vínculo estrecho y estable [del causante] con el Estado de que se trate" (Cons. [23] RES). Son los órganos jurisdiccionales nacionales de cada Estado miembro los competentes para determinar la residencia habitual del causante mediante el citado mecanismo de la "evaluación general".

2. La práctica legal internacional está plagada de casos extremadamente problemáticos en los que la precisión de la residencia habitual es realmente compleja. Algunos pueden destacarse.

$\left.1^{\circ}\right)$ Residencia habitual existente pero de compleja determinación. Enfoque general. Como se ha subrayado, determinar la residencia habitual del causante puede resultar realmente muy complejo. La vida de ciertos causantes puede estar conectada sustancialmente con varios y numerosos países al mismo tiempo. Por ello, en ciertos casos, dicha complejidad fáctica de la vida del causante obligará a la autoridad que conozca del 
asunto a desplegar una carga argumentativa más profunda (debe argumentar con mayor intensidad su posición jurídica). Sin embargo, esta complejidad no autoriza al juez o autoridad ante la que se haya presentado la demanda a prescindir de este foro (no es posible la "desactivación judicial" del foro de la residencia habitual del causante) y a optar por un non liquet ("no está claro") o por cualquier otro foro (Cons. [25] RES in fine por analogía). El juez debe siempre justificar la existencia o inexistencia de la residencia habitual del causante en un Estado miembro por difícil que resulte la argumentación.

$2^{\circ}$ ) Residencias habituales internacionalmente disociadas (residencia habitual profesional / residencia habitual familiar). En los casos de "residencias habituales internacionalmente disociadas" surgen, efectivamente, agudos problemas legales. En ciertos supuestos, el causante dispone de su "residencia profesional / residencia económica" en un Estado pero también tiene una "residencia familiar / residencia social" en otro Estado distinto. En estos casos, el causante dispone de una sede o residencia en un concreto país por motivos profesionales o económicos (país donde trabaja, donde tiene sus recursos financieros, donde dispone de su sede profesional o empresarial, donde además suele tener un cierto patrimonio, incluso inmueble), pero conserva, igualmente, una residencia en otro Estado (la residencia de su familia) que suele ser su Estado de origen. Ello pone de relieve que el causante mantiene también un vínculo estrecho y estable con dicho Estado de origen. En tal caso, y aunque la solución concreta siempre debe depender del caso particular del que se trate, podría considerarse que el causante tenía su última residencia habitual en su Estado de origen. Ello es así porque, como antes se ha dicho, es relevante el Estado miembro en el que estaba situado el "centro de interés de su familia y su vida social" (Cons. [24] RES), más que el Estado donde radican los intereses profesionales, económicos, financieros o patrimoniales del causante.

$\left.3^{\circ}\right)$ Residencias alternativas y contemporáneas del causante. Los casos de residencias habituales alternativas del causante (éste, en realidad, vive en dos Estados miembros diferentes al mismo tiempo, pues dispone de dos centros familiares y sociales), pueden ser frecuentes, como indicó hace años Cavers (1971-1972: 475-493). En tales supuestos, ciertos "factores especiales" (de mayor peso en el razonamiento propio del mecanismo de la "evaluación general") deben tomarse en cuenta. El Cons. [24] RES se refiere a: (a) La nacionalidad del causante; (b) El país de situación de los bienes de la herencia. De tal modo, si el causante tiene la nacionalidad de uno de los Estados en los que reside o tiene sus principales bienes en uno de estos Estados miembros, la nacionalidad de aquél o la localización de dichos bienes podrían constituir un factor especial en la evaluación general de todas las circunstancias objetivas.

$\left.4^{\circ}\right)$ Residencias intermitentes pero muy continuadas. Este caso se plantea, por ejemplo, cuando un sujeto viaja casi todos los fines de semana del año a un país donde mantiene ciertas relaciones personales o sociales. En tal supuesto, debe estimarse que el sujeto dispone de una "presencia física duradera" en dicho país. A partir de ahí, habrá que valorar si dicha presencia es además una presencia integrada en la sociedad de dicho país y si tiene intención de habitar permanentemente en dicho Estado. Sólo en ese caso, tendrá su residencia habitual en el mismo.

$\left.5^{\circ}\right)$ Residencias - estancias intermitentes pero poco continuadas. Este supuesto surge cuando un sujeto viaja de vez y por cortos períodos de tiempo, como un fin de semana, a un país determinado. En este caso, el sujeto no dispone de una "presencia física duradera" en dicho país, por lo que no cumple con el aspecto cuantitativo de elemento objetivo de la residencia habitual. No manifiesta domus colere en dicho Estado. 
$\left.6^{\circ}\right)$ Causantes sin residencia permanente en un concreto país. Estos casos suscitan problemas de gran envergadura. Podría pensarse que un sujeto que no tiene residencia permanente en ningún Estado en concreto no puede tener el centro de su vida familiar o social en ningún país. En consecuencia, no tendría ninguna residencia habitual en un Estado miembro, de modo que no deberían operar ni el art. 4 RES ni el art. 21 RES. Frente a ello, de modo extraño, el Cons. [24] RES considera que se puede emplear la nacionalidad del causante y el país de situación de los bienes de la herencia como "factores especiales" para determinar el Estado miembro de la residencia habitual del causante. De todos modos, y pese a lo que este Considerando indica con escasa precisión, no se debe forzar el criterio, pues se podría tergiversar su sentido. Si un sujeto no posee su centro social de vida en un Estado miembro, aunque el mismo tenga la nacionalidad de un Estado miembro o bienes en el territorio de un Estado miembro, el art. 4 RES no otorgará competencia judicial internacional a ningún tribunal de ningún Estado miembro. Deberá entonces recurrirse a los demás foros de competencia internacional sucesoria. En cuanto a la Ley aplicable, deberá buscarse un criterio subsidiario a la residencia habitual para determinar la Ley aplicable a la sucesión mortis causa. Puede, en tal caso, utilizarse el art. 21.2 RES. No se trata de una aplicación analógica del precepto, sino de un recurso último (extrema ratio) al principio inspirador del art. 21.2 RES ante una laguna del Reglamento 650/2012. Se recurre, pues, ante la falta de una residencia habitual concreta del causante en un país determinado, al principio de la "vinculación más estrecha" del causante con un Estado. Téngase presente también la colocación sistemática del párrafo 2 del art. 21 RES sugiere que éste puede ser empleado para los casos en los que falla la aplicación del párrafo 1 del mismo precepto (la residencia habitual del causante).

$7^{\circ}$ ) Supuestos de última residencia habitual de corta duración y disociación entre competencia judicial (residencia habitual) y Ley aplicable (Ley del Estado con el que el causante presenta un vínculo más estrecho). Si concurre el elemento objetivo de la residencia habitual, incluso en el supuesto de una presencia duradera aunque no muy prolongada en el tiempo en un Estado, y concurre igualmente, por otra parte, una integración social del sujeto y el elemento intencional o subjetivo de la residencia habitual, debe estimarse que el sujeto tiene su residencia habitual en dicho Estado. Ello puede verificarse, por ejemplo, en el supuesto de un médico italiano que trabaja en Milán y que recibe una oferta, que acepta, para trabajar en un puesto de mayor responsabilidad e ingresos más cuantiosos en una clínica española como cirujano plástico y con carácter permanente, pero que fallece diez meses después de haberse instalado en España con su familia. Su residencia habitual está en España porque su presencia física en España es duradera, está integrado en la sociedad española, y tenía intención de permanecer a habitar en España. En efecto, no es infrecuente que ciertos causantes hayan trasladado su residencia habitual a un nuevo Estado miembro "poco tiempo antes de su fallecimiento" (Cons. [25] RES). En tal caso, es claro que si el centro familiar y social del causante radica en el nuevo Estado miembro, el art. 4 RES otorga competencia judicial internacional a los tribunales de dicho Estado miembro para conocer de los litigios sucesorios. Y es claro, también, que la ley aplicable a la sucesión mortis causa, a falta de otra indicación del causante al respecto, es la Ley de la residencia habitual del mismo. Ahora bien, al tratarse de una residencia habitual "de corta duración", es muy posible que quede acreditado que el causante mantenía un vínculo manifiestamente más estrecho con su Estado de origen. En tal caso, la Ley reguladora de la sucesión será la Ley de este otro Estado (la Ley del Estado de origen del causante, que es el Estado con el que el causante mantenía un vínculo 
manifiestamente más estrecho: art. 21.2 RES). Sin embargo, en tal caso, los tribunales competentes son los tribunales del Estado miembro de la última residencia habitual del causante. Tales tribunales aplicarán una Ley extranjera al fondo de la sucesión (art. 21.2 RES) y no pueden "despojarse de su competencia judicial internacional" para trasladar la competencia judicial internacional sobre el asunto a los tribunales del Estado miembro de origen del causante.

$8^{\circ}$ ) Causantes que viven en un país los últimos años de su vida pero en "círculos nacionales cerrados" sin integración en la sociedad de dicho país. Existen supuestos de personas que habitan los últimos años de sus vidas en otro país diferente al país de su nacionalidad pero que no se integran en las estructuras básicas de ese país de "residencia". Tales sujetos se mueven en "círculos cerrados" formados por sus propios nacionales. No hablan el idioma del país de su residencia, no siguen las costumbres de dicho país, ni se relacionan con personas de dicho país. Compran en supermercados y otros negocios gestionados por gente de su país de origen y en los que se venden exclusivamente productos de su país de origen. Asisten exclusivamente a eventos relacionados con su país de origen. El causante habita en un país en el que no está realmente insertado desde un punto de vista social. En estos casos, varios datos deben considerase: (I) Con arreglo al Cons. [23] RES, no se puede apreciar un "vínculo estrecho y estable [del causante] con el Estado de que se trate". El vínculo puede que sea "estable", pero no es "estrecho"; (II) Además, el Cons. [24] RES no es aplicable a este supuesto. Dicho Considerando se refiere a casos en los que un sujeto puede "haber residido en diversos Estados alternativamente o viajado de un Estado a otro sin residir permanentemente en ninguno de ellos". Esto es, se refiere a casos problemáticos por falta de "estabilidad" en la residencia, no por falta de "profundidad" del vínculo del causante con el país donde habita (la residencia, en este caso, no refleja un vínculo "estrecho"); (III) El Reglamento 650/2012 [sucesiones mortis causa] carece de una solución expresa para estos casos. No resulta correcto forzar el significado de la residencia habitual del causante en estos supuestos. Es preferible estimar que el causante no tiene residencia habitual en ningún país. Para colmar la laguna del sistema competencial y conflictual del Reglamento 650/2012 [sucesiones mortis causa] que surge en estos casos, debe operarse en una doble dirección: (Primera) Dirección competencial. A efectos de competencia judicial internacional, al fallar el foro de la última residencia habitual del causante en un Estado miembro, debe activarse el art. 10 RES, de modo que serán competentes los tribunales del Estado miembro en el que se encuentren los bienes de la herencia (art. 10 RES) y si tal precepto no otorga competencia judicial internacional a los tribunales de ningún Estado miembro, ello significa que el litigio sucesorio deberá sustanciarse ante tribunales de terceros Estados; (Segunda) Dirección conflictual. El Reglamento 650/2012 [sucesiones mortis causa] carece de una norma de conflicto subsidiaria para el caso de que el causante no tenga residencia habitual en ningún país del mundo. En tal supuesto, puede recurrirse al principio general del Reglamento 650/2012 [sucesiones mortis causa] de los "vínculos más estrechos". El juez deberá sujetar la sucesión mortis causa a la Ley del país con el que presente la mayor vinculación o proximidad. Este principio inspira las dos conexiones recogidas por el Reglamento 650/2012 [sucesiones mortis causa] (nacionalidad del causante elegida por éste y residencia habitual del causante). El juez deberá proceder a una evaluación general de todos los elementos del supuesto y verificar las conexiones espaciales de éste con diversos países. De este modo, la aplicación a la sucesión mortis causa de la Ley del país con el que dicha sucesión presenta los vínculos más estrechos garantiza la previsibilidad de la Ley aplicable para causante, acreedores del causante y herederos. Para acreditar cuál es el país 
con el que la sucesión mortis causa presenta los vínculos más estrechos, el juez puede seguir los mismos pasos que deben observarse en la aplicación de la cláusula de excepción recogida en el art. 21.2 RES.

$\left.9^{\circ}\right)$ Causantes que disponen de una mera inscripción en el padrón municipal de un país. A efectos de los arts. 4 y 21 RES, es irrelevante el "domicilio fiscal" o "administrativo" del sujeto en un determinado Estado. Dicho "domicilio fiscal" o "administrativo" sólo surte efectos fiscales o administrativos y no efectos de Derecho Privado. En relación con España puede afirmarse que la "inscripción en el padrón municipal de habitantes" de un municipio español no supone, automáticamente, que dicho sujeto tenga su residencia habitual en España (STS CA 11 noviembre 2009, STS 14 septiembre 2009, STS CA 8 marzo 1983, STS 10 junio 1966, STS 4 mayo 1977, STS 15 noviembre 1991, STS 30 enero 1993, SAP Madrid 5 julio 2002). Debe recordarse que, tal y como han recogido varios medios informativos, numerosos españoles en paro, por lo general de origen marroquí, se empadronan en Ceuta y Melilla, pero viven en Marruecos porque, en general, los precios son más reducidos en Marruecos que en España. Estas personas suelen utilizar "pisospateras" en los figuran como residentes más de ocho personas al mismo tiempo. Más de 200 hijos de estos españoles que residen realmente en Marruecos cruzan cada día la frontera para ir al colegio en Ceuta y Melilla (diario El País, 2013). Con frecuencia, estos españoles mantienen su inscripción en los padrones municipales españoles para poder percibir subsidios y ayudas del Estado español. Sin embargo, al tratase de ayudas de escasa cuantía, no podrían sobrevivir dignamente en España, de modo que residen en verdad en Marruecos. De igual modo, pueden escolarizar a sus hijos en España. Desde 2008, la población de Ceuta ha crecido un 9,2\% y la población de Melilla lo ha hecho un 17,2\%. Numerosos trabajadores españoles musulmanes de origen marroquí, en efecto, que se encuentran en paro y que proceden de diversas regiones españolas crean artificialmente una residencia en Ceuta y Melilla, pero se instalan en Marruecos. Pues bien, estas personas tienen su residencia habitual en Marruecos y no en España, país donde carecen de presencia física, integración social y ánimo de residir con intención de permanencia.

\section{REFLEXIÓN FINAL}

Un sistema coherente, sencillo, efectivo y eficiente de Derecho internacional privado europeo es imprescindible para asegurar los derechos fundamentales de los ciudadanos europeos. En este contexto, las sucesiones internacionales juegan un papel de primer orden y su regulación no puede quedar confiada a un sistema estocástico. Las soluciones de Derecho internacional privado europeo deben ser previsibles. En esta línea, ciertos intérpretes, autorizados y solventes, desconfían, sin embargo, de conceptos líquidos como el concepto de última "residencia habitual del causante". No se trata de caer en visiones nietzscheanas y de afirmar que "toda convicción es una cárcel". Se trata de superar el "logocentrismo", de escapar de la "tiranía de los conceptos", esa tendencia típicamente occidental de la que tan acertadamente hablara el gran filósofo alemán Ludwig Klages en los años 20 y que consiste en situar el centro de cualquier texto o discurso en el logos, en la palabra o expresión verbal y escrita. En este sentido, una adecuada exégesis y una cuidada hermenéutica holística del Reglamento sucesorio europeo deben evitar que el discurso verbal, la discusión sobre el concepto, desplace a la realidad y se convierta en un ente artificial. Lo importante, si hay que ser derridaista, no es la palabra, no es la "última 
residencia habitual del causante", sino la realidad que expresa ese concepto. La función que realiza ese foro de competencia judicial internacional proporciona la guía segura para trazar los contornos razonables de dicho foro de competencia judicial internacional. En esa perspectiva, no resulta tan complicado segregar casos y casos, de modo que en la mayoría de los supuestos, la precisión del país donde el causante tuvo su última residencia habitual no será complicada. Para los hard cases, debe recurrirse a las soluciones más sensatas, al sentido común propio del Derecho internacional privado europeo, que indicará al intérprete que la residencia habitual del causante debe concretarse en el país donde la litigación entre las partes puede desarrollarse a un menor coste.

\section{BIBLIOGRAFÍA}

BONOMI, A. (2010). "Testamentary freedom or forced heirship" Balancing party autonomy and the protection of family members". Nederlands Internationaal Privaatrech, abril, pp. 605-610.

CARBONNIER, J. (1984). "Les notions à contenu variable dans le droit français de la famille", Travaux du Centre National de la recherche de la logique, Bruylant, pp. 99-121.

CAVERS, D. F. (1971-1972). "Habitual Residence: A Useful Concept?". The American University Law Review, pp. 475-493.

CEMBRERO, I. (2013). "La crisis dispara el crecimiento demográfico de Ceuta y Melilla". En: El País 9 diciembre 2013. Accesible en http://politica.elpais.com/politica/2013/12/09/actualidad/ 1386615099_229818.html (visitado 2/3/2015).

DAMASCELLLI, D. (2013). "I criteri di collegamento impiegati dal regolamento n.650/2012 per la designazione della legge regolatrice della successione a causa di morte", en P. Franzina y A. Leandro (a cura di) Il diritto internazionale privato europeo delle successioni mortis causa, Consiglio nazionale del notariato Collana Studi. Milano: Giuffrè, pp. 87-103.

DAVİ, A. y ZANOBETTI, A. (2013). "Il nuovo diritto internazionale privato delle successioni nell'Unione europea", $C D T$, vol. 5-II, en www.uc3m.es/cdt.

DE WINTER, L. I. (1969). "Nationality or domicile? The present state of affairs". RCADI, III, pp. 347-504.

DEVAUX, A. (2013). "The European Regulations on Succession of July 2012: A Path Towards the End of the Succession Conflicts of Law in Europe, or not?". The international lawyer, vol. 47, issue 2, Fall. http://papers.ssrn.com/sol3/papers.cfm?abstract_id=2230663.

ESPINAR VICENTE, J. M. (1980). "El concepto de residencia habitual en el sistema español de derecho internacional privado". Revista de derecho privado, pp. 3-27.

ESPINAR VICENTE, J. M. (1995). "Residencia habitual (Derecho internacional privado)", Enciclopedia Jurídica Básica. Madrid: Civitas, pp. 5876-5880.

ESPINAR VICENTE, J. M. (1995). "Nacionalidad”. Enciclopedia Jurídica Básica Madrid: Civitas, pp. 4379-4385.

FERACI, O. (2013). "La nuova disciplina europea della competenza giurisdizionale in materia di successioni mortis causa", $C D T$, febrero, pp. 291-314.

GAUDEMET-TALLON, H. (2004). "Quelques réflexions sur les propositions concernant la compétence judiciaire, la reconnaissance et l'exécution des décisions en matière successorale dans l'Union européenne", en DNotI, Les Successions Internationales dans l'UE, pp. 445-459 en http://www.successions.org/.

GAUDEMET-TALLON, H. (2013). "Les règles de compètence judiciarie dans le règlement européen sur les successions", en G. Khairallah y M. Revillard (dirs.) Droit européen des successions internationales (Le Règlement du 4 juillet 2012). París: Defrénois, pp. 127-140.

LAGARDE, P. (2005). "Vers un Règlement communautaire du Droit international privé des régimes matrimoniaux et des successions", en Pacis Artes, vol. II, Madrid, pp. 1686-1708.

LAGARDE, P. (2012). "Les principes de base du nouveau réglement européen sur les successions", $R C D I P$, junio, pp. 691-732. 
LAGARDE, P. (2013). "Présentation du règlement sur les successions", en G. Khairallah y M. Revillard (dirs.) Droit européen des successions internationales (Le Règlement du 4 juillet 2012). París: Defrénois, pp. 5-16.

NOURISSAT, C. (2013). "Le champ d'application du règlement", en G. Khairallah y M. Revillard (dirs.) Droit européen des successions internationales (Le Règlement du 4 juillet 2012). París: Defrénois, pp. 17-36.

RICHEZ-PONS, A. (2005). "La notion de résidence", en H. Fulchiron y C. Nourissat (dirs.) Le nouveau droit communautaire du divorce et de la responsabilité parentale. Dalloz, pp. 149-160.

VAN HOOGSTRATEN, M.H. (1967). "La codification par Traités en droit international privé dans le cadre de la Conférence de La Haye", RCADI, vol.122, pp. 337-435.

\section{Breve currículo:}

\section{Javier Carrascosa González}

Catedrático de Derecho internacional privado, Universidad de Murcia. Autor de ocho monografías relativas al Derecho internacional privado, Tratado sobre Derecho de la Competencia en la UE y de un manual de Derecho internacional privado español en dos volúmenes (junto con el Dr. A. L. Calvo Caravaca), (15 edición), Granada, 2014. Autor de numerosas publicaciones especializadas en el campo del Derecho internacional privado. Publicaciones de investigación jurídica en España, Alemania, Gran Bretaña, Italia, Portugal, Francia, Estados Unidos, Argentina, Méjico, Colombia, Chile y Uruguay. Idiomas: Inglés, italiano y español. Líneas de investigación principales: Derecho de familia internacional, Derecho sucesorio internacional, Derecho de la contratación internacional, Derechos de la personalidad en el contexto internacional, Derecho internacional privado de sociedades, Derecho procesal civil internacional. Asesor del Ministerio de Justicia y representante de España en la negociación del Reglamento "Roma III" (Ley aplicable al divorcio: años 2005 al 2008). Asesor de la Dirección General de los Registros y del Notariado (2004-2009). Visiting Professor en la Università di Cagliari, Italia (julio 2008 y julio 2010). Profesor conferenciante "Programa Erasmus para profesores" en la Universidad de Roma III (mayo del 2010 al 2013 y abril 2014). 